\title{
Designing cases in problem-based learning to foster problem-solving skill
}

\author{
Margaret C. Lohman ${ }^{1}$ and Michael Finkelstein ${ }^{2}$ \\ ${ }^{1}$ College of Behavioural Sciences and Education, Penn State Capital College, Middletown, PA 17057, USA; \\ ${ }^{2}$ College of Dentistry, University of Iowa, Iowa City, Iowa 52242, USA
}

\begin{abstract}
The purpose of this study was to examine the effect of case segmentation schemes in problem-based learning (PBL) on the development of problem-solving skill, self-directedness and technical knowledge. Seventy-four dental education students were randomly assigned to $12 \mathrm{PBL}$ groups. Six groups experienced PBL cases that were formatted in short segments and six groups experienced PBL cases that were formatted in long segments. Pretest measures of problem-solving skill, self-directedness and technical knowledge were administered at the beginning of the Fall 1998 semester. Students studied three PBL cases in their assigned groups in the ensuing semester. Posttest measures were administered at the conclusion of the semester. Analysis of the data found that students who experienced PBL with a short case segmentation scheme were better able to solve
\end{abstract}

problems highly similar to the problems in the teaching cases than students who experienced PBL with a long case segmentation scheme. No significant differences were found for selfdirectedness, technical knowledge, or ability to solve problems distinctly different from the teaching cases. Explanations of these findings and their implications for research and practice in PBL are discussed.

Key words: problem-based learning; problem-solving instruction; case tutorials.

(C) Blackwell Munksgaard 2002

Accepted for publication 6 September 2001
$\mathrm{P}$ ROBLEM SOLVING is a critical aspect of professional practice (1). Professionals must be able to interpret ambiguous, novel and conflicting situations that they regularly face in their work (2). These types of situations, commonly referred to as ill-structured problems, lack clear identification of the problem, procedures for identifying solutions and criteria for evaluating solutions (3).

Increasingly, professional education programmes are recognizing the need for professionals to be able to solve ill-structured problems and are incorporating instructional experiences into their curricula to help students develop problem-solving skill (4). One such instructional method is problem-based learning (PBL). PBL is presently used in more than 60 schools of medicine world-wide, and is commonly found in schools of dentistry, pharmacy, optometry, nursing, law, business and education (5).

The goals of PBL include the development of problem-solving skill, self-directedness and technical knowledge (knowledge of facts, concepts and rules) in a professional area (6-8). Achievement of these goals is accomplished by having learners work together to analyse a problem routinely faced in professional practice (9). Specifically, the instructional events of PBL lead learners through the steps of problem solving in illstructured situations. These events include a discussion of the facts - what is known about the problem, information gaps - what information is needed but not known, hypotheses - a list of possible causes or explanations of the problem, and learning issues - areas where learners lack knowledge. Learners independently research learning issues in-between training sessions and use their new learning in subsequent sessions to critique and select emerging hypotheses about the problem's causes and solutions. Typically, a number of solutions emerge to form an appropriate conclusion to the problem (6).

A distinctive element of PBL is the focus on problems as the basis for learning in the instructional experience. Instructional cases are the vehicle for presenting problems to learners in PBL. Two aspects of a case are of paramount importance in PBL: content and format. With regard to content, it is generally accepted that PBL cases should be prototypic, that is, an example of a routine problem seen in practice which contains a high 
number of critical features (for example, signs, symptoms and causes) in common with other examples of that type of problem (4). In addition to prototypic features, PBL cases should be fairly challenging and complex, so that they have a fairly high degree of fidelity and create sufficient cognitive dissonance to motivate learners (6). Although there is fairly widespread acceptance as to what type of content should be presented in PBL cases, there is much less agreement about how that content should be formatted (9).

One perspective asserts that case information should be formatted in long segments. With a long segmentation scheme, learners actively organize and interpret large chunks of case information to identify problem goals, facts, constraints and solution procedures (9). These cognitive activities result in the development of a schema or mental representation of a particular type of problem. A schema can be activated when a similar problem is encountered, enabling a problem solver to move directly from the representation of the problem to the implementation of solution procedures (10).

However, a different perspective asserts that problem-solving skill and self-directedness are better promoted when case information is formatted in short segments. With a short segmentation scheme, the amount of information and the order in which it is presented is based on the typical amount and order of information that professionals utilize when they work on such a problem. Short segmentation schemes help learners focus on critical information in problems and the key steps of the problem-solving process (11). This assistance is believed to promote the development of problem-solving skill and self-directedness (12).

Given these conflicting perspectives and the scarcity of empirical studies on this topic, specific recommendations for formatting cases in PBL are premature at present. Therefore, the purpose of this study was to gain a greater understanding of the role of case segmentation schemes in PBL by examining their impact on the development of problem-solving skill, selfdirectedness and technical knowledge in a professional education programme.

\section{Purpose of the study and research questions}

The purpose of this study was to examine the effect of case segmentation schemes in PBL on the development of problem-solving skill, self-directedness and technical knowledge. The following research questions were examined:

1. Will students receiving PBL case information in short segments develop significantly greater ability to solve problems highly similar to the problems in the teaching cases (near transfer) than students receiving case information in long segments?

2. Will students receiving PBL case information in short segments develop significantly greater ability to solve problems distinctly different from the problems in the teaching cases (far transfer) than students receiving case information in long segments?

3. Will students receiving PBL case information in short segments develop a significantly higher level of self-directedness than students receiving information in long segments?

4. Will students receiving PBL case information in short segments acquire a significantly higher level of technical knowledge than students receiving information in long segments?

\section{Methods}

\section{Population and sample}

The target population in this study were students enrolled in professional education programmes. The sample consisted of 74 first-year dental education students enrolled in a histology course at a large Midwest University in the US during the 1998-1999 academic year. Although participation in PBL was a mandatory part of this course, student participation in the research project was voluntary. All 74 students agreed to participate in the study.

Of these 74 dental students, 49 were males and 25 were females. The mean age was 24.3 years $(\mathrm{SD}=2.86$ ). Seventy-seven per cent of the students had a bachelor's degree, $17.6 \%$ of the students had a high school education and at least 3 years of post-secondary education, and a small percentage of students had either a master's degree $(2.7 \%)$ or a doctoral degrees $(2.7 \%)$.

\section{Research design}

Two case segmentation schemes were examined: long and short. As shown in Table 1, a long segmentation scheme describes a format in which the content of the case is presented to learners in large chunks. In the present study, the content for the long segmentation scheme was presented in four main parts. Conversely, a short segmentation scheme describes a format in which the content of the case is presented in small segments. The short segmentation scheme, in this study, contained 10 parts. Note that the total amount of case information in both segmentation schemes was the same; the difference lay in the amount of information presented in each instructional chunk.

A pretest-posttest control group design was used to investigate the effect of long versus short case 
TABLE 1. Case information contained in the different parts of the long and short segmentation schemes

\begin{tabular}{|c|c|c|c|c|}
\hline \multirow[t]{3}{*}{ Type of information } & \multicolumn{4}{|c|}{ Case segmentation schemes } \\
\hline & \multicolumn{2}{|c|}{ Long } & \multicolumn{2}{|c|}{ Short } \\
\hline & Part & Content & Part & Content \\
\hline \multirow[t]{2}{*}{ Patient history } & 1 & $\begin{array}{l}\text { Patient description, chief complaint, } \\
\text { medical history and physical exam }\end{array}$ & 1 & Patient description, chief complaint \\
\hline & 2 & $\begin{array}{l}\text { Psychological and social history, } \\
\text { dietary history and dental history }\end{array}$ & 2 & Medical history and physical examination \\
\hline \multirow[t]{2}{*}{ Diagnosis } & 3 & $\begin{array}{l}\text { Clinical examination, } \\
\text { dental examination and diagnosis }\end{array}$ & 6 & Clinical examination \\
\hline & & & $\begin{array}{l}7 \\
8\end{array}$ & $\begin{array}{l}\text { Dental examination } \\
\text { Diagnosis }\end{array}$ \\
\hline Treatment & 4 & $\begin{array}{l}\text { Treatment plan approaches, } \\
\text { specification of a treatment plan and } \\
\text { prioritization of interventions in plan }\end{array}$ & $\begin{array}{r}9 \\
10\end{array}$ & $\begin{array}{l}\text { Treatment plan approaches } \\
\text { Specification of a treatment plan and } \\
\text { prioritization of interventions in plan }\end{array}$ \\
\hline
\end{tabular}

segmentation schemes in PBL on the development of problem-solving skill, self-directedness and technical knowledge (13). With this design, 74 students were randomly assigned to 12 PBL groups. Six groups experienced PBL with a short case segmentation scheme and six groups experienced PBL with a long case segmentation scheme. Each PBL group was composed of six to seven students and a trained facilitator. Pretest measures of problem-solving skill, self-directedness and technical knowledge were administered at the beginning of the Fall 1998 semester. Students studied three cases in their assigned PBL groups in the ensuing semester. Each of the three cases lasted three class sessions, with each session lasting approximately $2 \mathrm{~h}$. Posttest measures were administered at the conclusion of the Fall semester. The student composition of PBL groups within each case segmentation scheme was rearranged through random assignment after each three-session PBL in order to minimize a group or facilitator effect in the study.

The PBL-teaching cases were complex, but prototypic in that they had a high number of dental and medical features in common with patients routinely seen in dental practice. The content of the cases was written and validated by two faculties in the college of dentistry at the participating university. The instructional events of this PBL programme followed the protocol established by Barrows (6), which includes discussion and analysis of facts, information gaps, hypotheses and learning issues related to the patient case. The instructional design was judged sound by a faculty member in the college of education who had extensive experience with the design and research of PBL programmes.

Six facilitators participated in the study. They were either dental school faculties or advanced graduate students preparing for academic careers in dental education. Each of the six facilitators was randomly assigned to two PBL groups, one group which experienced the short case segmentation scheme and one group which experienced the long case segmentation scheme. The assignment of facilitators to both types of case segmentation schemes minimized the likelihood that any one facilitator would differentially impact one level of the treatment. All facilitators attended a training session which focused on the facilitator's role, the instructional objectives, the expected learning outcomes and appropriate structured questions for facilitating problem analysis in PBL. The facilitators were responsible for monitoring the pace of their groups through the various stages of PBL, encouraging all students to be actively involved, encouraging students to express their thoughts, and critically responding to the comments of students (14). Throughout the semester, facilitators met weekly to review the PBL cases and objectives and discuss instructional problems and concerns.

\section{Outcome measures}

The following outcome measures were examined in this study: problem-solving skill, self-directedness and technical knowledge.

\section{Problem-solving skill}

Although PBL may be used in some instructional situations to enhance group problem-solving and teamwork skills, it is predominantly used in professional education programmes, including the dental education programme in this study, to develop individual problem-solving skill and self-directedness (6). As such, problem-solving skill was evaluated through a 
modified version of the triple-jump evaluation activity (15). A triple-jump evaluation involves presenting a student with a case that details a patient's chief complaint, medical history and information obtained from a physical examination. Time is then provided for the student to conduct independent research on issues related to the case. After several hours to several days, the student reports back to an evaluator with hypotheses about a diagnosis and a treatment plan.

In the present study, two assessment cases were administered in the class at the beginning and conclusion of the Fall semester. Students were allowed to use the recommended textbook for the course, which contained information required to derive appropriate diagnoses and treatment plans for the cases as well as other supplemental information not relevant to the cases. Students had an unlimited amount of time to work independently on and respond to case questions.

Problem-solving skill was measured by the degree to which students could solve problems that were either highly similar or distinctly different from the problems in the teaching cases. The problems in the near-transfer assessment cases shared a high number of critical features (9) in common with the teaching cases. The far-transfer assessment cases shared only two critical features in common with the teaching cases. These critical features represented the common signs, symptoms and causes of the diseases that were presented in the teaching cases. The course instructor used a rating form to score the students' responses to the assessment cases. Total possible points ranged from 0 to 8 for the transfer cases.

The validity of the near- and far-transfer assessment cases was confirmed by two members of the dental faculty. Coefficients of stability were established through a test-retest procedure, whereby the course instructor scored, and then 10 days later, re-scored the same 15 randomly selected responses for each of the four cases. The coefficients of stability were very high, with Pearson's product-moment correlation coefficients ranging from 0.70 to 0.92 . To establish interrater reliability, two dental faculty independently scored 15 randomly selected responses for each of the four cases. Interrater reliability coefficients were also very high, ranging from 0.73 to 0.78 .

\section{Self-directedness}

The self-directed learning readiness scale (SDLRS-A) was used to assess self-directedness (16). The SDLRS-A is a 58-item self-report instrument, designed to measure the complexities of attitudes, abilities and characteristics which comprise readiness to engage in self-directed learning. This instrument has been widely used to examine the self-directedness of adults in professional areas such as medicine and business. Its validity and reliability have been extensively documented (17). Total possible scores on the SDLRS range from 0 to 290.

\section{Technical knowledge}

Two parallel forms of a 12-item multiple-choice test were used to assess knowledge of the facts, concepts and rules that were covered in the three PBL-teaching cases during the semester. The tests were administered at the beginning and end of the Fall semester. Total possible scores on both forms of the technical knowledge test ranged from 0 to 12 . The internal consistency of the multiple-choice instruments was very high, with a split-half correlation analysis yielding reliability coefficients of $0.86-0.90$.

\section{Results}

Four hypotheses were tested to examine the effect of case segmentation scheme on near and far transfer of problem-solving skill, self-directedness and technical knowledge. An alpha level of 0.05 was established, a priori, for the statistical tests. The $t$-tests were first used to examine whether mean pretest scores of the dependent variables differed significantly for students experiencing short and long case segmentation schemes. Because no significant differences were found between the two segmentation schemes on any of the pretest scores, $t$-tests of gain scores were used to examine the effect of case segmentation scheme on each of the dependent variables (18) (refer Table 2 for the results of these tests).

\section{Transfer of problem-solving skill}

A $t$-test revealed that students experiencing PBL with a short case segmentation scheme improved their ability to solve near-transfer problems to a significantly greater degree $(M=4.7, \mathrm{SD}=2.43)$ than those experiencing a long case segmentation scheme $(M=3.3$, $\mathrm{SD}=3.12), t=2.26, P<0.05$.

However, no significant difference was found between the two case segmentation schemes for far transfer of problem-solving skill. Far-transfer scores increased an average of 1.9 points $(S D=2.74)$ for students experiencing a short segmentation scheme and an average of 1.5 points $(\mathrm{SD}=2.82)$ for those experiencing a long segmentation scheme, $t=0.59$.

\section{Development of self-directedness}

No significant difference was found for case segmentation scheme on the development of self-directedness. 
TABLE 2. Effect of case segmentation schemes on selected PBL outcomes

\begin{tabular}{|c|c|c|c|c|c|}
\hline \multirow[t]{3}{*}{ PBL outcomes } & \multicolumn{4}{|c|}{ Case segmentation schemes } & \multirow[t]{3}{*}{$t$} \\
\hline & \multicolumn{2}{|l|}{ Short } & \multicolumn{2}{|l|}{ Long } & \\
\hline & M & SD & $M$ & SD & \\
\hline \multicolumn{6}{|l|}{ Problem-solving } \\
\hline \multicolumn{6}{|l|}{ Near transfer } \\
\hline Pretest & 2.5 & 1.35 & 3.2 & 1.97 & \\
\hline Posttest & 7.2 & 2.11 & 6.5 & 2.57 & \\
\hline Gain score & 4.7 & 2.43 & 3.3 & 3.12 & $2.26^{*}$ \\
\hline \multicolumn{6}{|l|}{ Far transfer } \\
\hline Pretest & 4.1 & 1.93 & 4.1 & 1.93 & \\
\hline Posttest & 6.0 & 2.30 & 5.6 & 2.44 & \\
\hline Gain score & 1.9 & 2.74 & 1.5 & 2.82 & 0.59 \\
\hline \multicolumn{6}{|c|}{ Self-directedness } \\
\hline Pretest & 231.6 & 20.62 & 235.3 & 17.30 & \\
\hline Posttest & 235.4 & 20.13 & 233.2 & 21.07 & \\
\hline Gain score & 3.8 & 12.70 & -2.1 & 15.29 & 1.83 \\
\hline \multicolumn{6}{|c|}{ Technical knowledge } \\
\hline Pretest & & & & & \\
\hline Posttest & 9.0 & 1.41 & 8.6 & 1.38 & \\
\hline Gain score & 1.7 & 1.64 & 1.0 & 2.11 & 1.54 \\
\hline
\end{tabular}

${ }^{*} P<0.05$.

Students' levels of self-directedness increased by an average of 3.8 points $(\mathrm{SD}=12.70)$ for students experiencing a short segmentation scheme and decreased by an average of 2.1 points $(S D=15.29)$ for those experiencing a long segmentation scheme, $t=1.83$.

\section{Acquisition of technical knowledge}

Furthermore, no significant difference was found for case segmentation scheme on the acquisition of technical knowledge. These scores increased an average of 1.7 points $(\mathrm{SD}=1.64)$ for students experiencing a short segmentation scheme and an average of 1.0 point $(\mathrm{SD}=2.11)$ for those experiencing a long segmentation scheme, $t=1.54$.

\section{Discussion}

The first year of professional education in the health sciences traditionally focuses on memorization of factual material. One of the primary goals of PBL is to broaden this focus by providing instructional experiences that promote the development of problem-solving and independent learning skills. The purpose of the present study was to understand further the effect of case segmentation schemes in PBL on the development of these higher-level cognitive skills. Analysis of the data found that a short case segmentation scheme resulted in significantly greater gains in students' ability to solve problems highly similar to the problems in the teaching cases (near transfer) than did a long segmentation scheme. However, no significant differences were found for case segmentation scheme on technical knowledge or self-directedness. Possible explanations for these findings and their implications for research and practice in PBL are presented in this section.

The ability to solve near-transfer problems improved to a greater degree for students who experienced a short case segmentation scheme as opposed to those who experienced a long case segmentation scheme. A likely explanation for this finding relates to the types of cognitive strategies that are used to solve problems. A schema-driven strategy is used to move quickly from the identification of a problem to the selection and implementation of solution procedures (19). The successful use of a schema-driven strategy requires the existence of a schema containing information regarding problem goals, constraints and solution procedures (10). It is possible that the structure and guidance provided by the short case segmentation scheme enabled learners to develop more sophisticated schemata for the types of problems represented in the teaching cases (9). Students were then able to activate these schemes when solving similar types of problems in the near-transfer assessment cases.

However, no significant differences were found on far transfer of problem-solving skill. In contrast to the schema-driven strategy, problem solvers typically use a general search strategy called a means-end analysis when dealing with unfamiliar problems (20). A means-end analysis is a form of backward reasoning, in which the signs and symptoms of a problem are compared to a broad list of possible causes of that problem (6). This list is gradually narrowed down through the collection and analysis of relevant information. Ultimately, as Gilhooly (21) postulates, causes with low match rates to the presenting signs and symptoms are ruled out and causes with high match rates are retained. This process continues until one or several appropriate solutions emerge. This backward reasoning process is highly similar to the problemsolving process that students in the current study used to solve the unfamiliar problems in the far-transfer assessment cases. Because general search strategies do not rely on the existence or activation of relevant schemes, it stands to reason that no significant differences were found between the two case segmentation schemes on far transfer of problem-solving skill.

In addition, no significant differences were found for self-directedness between short and long case segmentation schemes. A possible explanation for this finding 
is that all students, regardless of which case segmentation scheme they experienced, were responsible for identifying and independently researching learning issues as part of the PBL experience. Facilitators monitored the assignment of issues to students to ensure that the independent research assignments of participants in both case segmentation schemes were of comparable depth and breadth. As a consequence, students' ability or desire to engage in independent learning activities was not differentially affected by the case segmentation scheme that they experienced.

A somewhat surprising finding was that the development of technical knowledge was negligible for students in both the case segmentation schemes. A criticism of PBL has been that students experiencing this instructional method tend to perform more poorly on standardized examinations than students who have gone through traditional professional education programmes (6). A possible explanation for the current finding is that the development of technical knowledge as an objective of PBL was not explicitly communicated to students. It is possible that students did not devote the time and energy outside the class time to learn the technical information in the case simply because they did not know that they were supposed to and/or were not examined over it as part of their class grade. This is an important issue in improving the quality of PBL, because it has been clearly documented that an extensive knowledge base in a technical domain is a requirement for expert problem solving $(1,22)$. The importance of the acquisition of technical knowledge as a learning outcome continues to grow as more professional education programmes integrate PBL into their curriculum.

\section{Implications for designing $P B L$}

PBL must be designed so that it provides the necessary conditions for learning to occur. Three implications for designing PBL programmes have emerged from this study. First, a short case segmentation scheme should be used to format PBL cases. Greater gains in students' ability to solve problems highly similar to the teaching cases were found with a short case segmentation scheme. This finding implies that a short case segmentation scheme helps individuals develop and use schemes effectively and efficiently to solve problems routinely seen in practice.

Second, instructional support should be provided to help students achieve all of the stated objectives of PBL, including the development of technical knowledge. One way to facilitate the development of technical knowledge is to provide students with performance objectives for each PBL case (6). These objectives would identify what students should know and be able to do after the completion of the case. The contention is that if the expectations for the development of technical knowledge are explicitly communicated to students through these objectives, then students will do a better job of learning that type of knowledge.

Third, guidance should be provided to help learners engage in meaningful independent learning. Two forms of guidance are recommended. Prior to independent learning activities, discussions should be held in which participants share ideas about the types and locations of learning resources that might prove useful in learning more about assigned learning issues (14). After independently researching their learning issues, PBL participants should evaluate the quality and accessibility of learning resources that were used. These preparation and evaluation activities will help promote students' ability and desire to direct and manage their own learning.

\section{Future research of $P B L$}

Further research in three areas would deepen present understanding of the interplay between design components and desired outcomes of PBL. First, this study should be replicated with more advanced students in professional education programmes. It has been clearly documented that individuals with varying levels of expertise use different types of cognitive strategies to solve complex problems $(1,22)$. Participants in the current study were students at the beginning of their dental education. Replication of this study with more advanced students would help determine the degree to which case segmentation schemes differentially influence learning outcomes for participants with greater levels of technical expertise. A second area for future research is the exploration of instructional aids, such as lists of competencies and instructional objectives, in facilitating the concomitant development of technical knowledge and problem-solving skill. Third, further research on independent learning activities and their role in developing problem-solving and independent learning skills in PBL should be conducted. Variables of particular interest include the types and levels of guidance that are provided in PBL to help learners identify, locate and evaluate learning resources.

\section{References}

1. Bereiter C, Scardamalia M. Surpassing ourselves: an inquiry into the nature and implications of expertise. Chicago: Open Court, 1993.

2. Schön DA. Educating the Reflective Practitioner. San Francisco: Jossey-Bass, 1987. 
3. Frederiksen N. Implications of cognitive theory for instruction in problem solving. Rev Educ Res 1984: 54(3): 363-407.

4. Mandin H, Jones A, Woloschuk W, Harasym P. Helping students learn to think like experts when solving clinical problems. Acad Med 1997: 72(3): 173-179.

5. Savery JR, Duffy TM. Problem-based learning: an instructional model and its constructivist framework. Educ Technol 1995: September-October: 31-38.

6. Barrows HS. Practice-based learning: problem-based learning applied to medical education. Springfield, IL, USA: Southern Illinois University School of Medicine, 1994.

7. Delisle R. How to use problem-based learning in the classroom. Alexandria, VA, USA: Association for Supervision and Curriculum Development, 1997.

8. Gallagher SA. Problem-based learning: where did it come from, what does it do, and where is it going? J Educ Gifted 1997: 20(4): 332-362.

9. Albanese MA, Mitchell S. Problem-based learning: a review of literature on its outcomes and implementation issues. Acad Med 1993: 68(1): 52-81.

10. Gick ML. Problem-solving strategies. Educ Psychol 1986: 21(1/2): 99-120.

11. Pawlak SM, Popovich NG, Blank JW, Russell JD. Development and validation of guided design scenarios for problem-solving instruction. Am J Pharmaceut Educ 1989: 53: 7-16.

12. Jones JW, Bieber LL, Echt R, Scheifley V, Ways PO, . A problem-based curriculum - ten years of experience. In: Schmidt, HG, d Volder, ML, eds. Tutorials in problembased learning. Maastricht, the Netherlands: Van Gorcum, 1984: 181-198.

13. Campbell DT, Stanley JC. Experimental and quasiexperimental designs for research. Chicago: McNally, 1963.
14. Hmelo CE, Ferrari M. The problem-based learning tutorial: cultivating higher order thinking skills. J Educ Gifted 1997: 20(4): 401-422.

15. Friedman CP, Murphy GC, Smith AC, Mattern WD. Exploratory study of an examination format for problembased learning. Teach Learn Med 1994: 6(3): 194-198.

16. Guglielmino LM. Self-directed learning readiness scale. Boca Raton, FL, USA, 1995.

17. Guglielmino L. Reliability and validity of the selfdirected learning readiness scale and the learning preference assessment. Paper presented at the tenth international symposium on self-directed learning. West Palm Beach, FL, USA, March, 1996.

18. Fraenkel JR, Wallen NE. How to design and evaluate research in education. New York: McGraw-Hill, 1990.

19. Palumbo DB. Programming language/problem solving research: a review of relevant issues. Rev Educ Res 1990: 60(1): 65-89.

20. Patel VL, Groen GJ, Norman GR. Effects of conventional and problem-based medical curricula on problem solving. Acad Med 1991: 66: 380-389.

21. Gilhooly KJ. Cognitive psychology and medical diagnosis. Appl Cognit Psychol 1990: 4: 261-272.

22. Chi MTH, Glaser R, Farr MJ. The nature of expertise. Hillsdale, NJ, USA: Erlbaum, 1988.

Address:

Dr Michael Finkelstein

357 Dental Science South

College of Dentistry

University of Iowa

Iowa City, IA 52242-1001

USA

Tel.: +13193357360

Telefax: +13193357351 